\title{
Proyecto de digitalización y recuperación del material gráfico y documental perteneciente al Archivo de Arquitectura Chilena
}

MARía PAZ VALENZUELA BLOSSIN / COORDINADORA ARCHIVO DE LA ARQUITECTURA CHILENA, DEPARTAMENTO DE HISTORIA Y TEORIA DE LA ARQUITECTURA

El Archivo de Arquitectura Chilena depende del Departamento de Historia y Teoría de la Arquitectura que fue creado en 1952 en la Facultad de Arquitectura y Urbanismo de la Universidad de Chile, siendo esta Escuela de Arquitectura la más antigua del país, creada en 1849 al alero de la propia universidad.

Con este bagaje y tradición histórica es que se crea el año 2002 este Archivo basado en la concentración a lo largo de su existencia, de una gran cantidad de documentos inéditos sobre la historia de la arquitectura chilena, los que corresponden indudablemente al material más completo que existe sobre esta materia, a nivel nacional y cuyo resguardo nos permitirá legarlos a las futuras generaciones.

Conscientes del valor histórico y documental del material custodiado y de la conformación y trayectoria de nuestro Archivo, nos atrevimos a postular en el año 2008 a un concurso convocado por la Asociación de Archivos Iberoamericanos (ADAI), que con el financiamiento de la Agencia Española de Cooperación Iberoamericana (AECI) nos permitió obtener recursos para restaurar y poner en valor parte de la colección custodiada. Ello, sumado a la digitalización de este material, permitiría mejorar la consulta y evitar el deterioro de estos valiosos documentos.

A la fecha contamos con un número importante de Seminarios, diapositivas, planos y otros elementos restaurados y digitalizados, que además están disponibles para su consulta y reproducción.

De manera complementaria y como una apuesta que nos permitiera llevar nuestro Archivo fuera de las paredes de la facultad, se generó una página web como soporte del material documental (ardach. uchilefau.cl). Esta página permite revisar el material digitalizado y clasificado, evitando el deterioro, además de estar en permanente actualización e incorporación de nuevos documentos.

Respecto de nuestra página podemos señalar que ella permite buscar el material a través de diversas clasificaciones de materia o soporte, junto con ello cuenta con secciones como los Fondos -que agrupan el material de arquitectos o temas en particular-y secciones como patrimonio joven, con los mejores proyectos de título, o patrimonio actual que presentará en el futuro los proyectos más relevantes de arquitectura contemporánea.

Luego de los alcances logrados con este proyecto, pudimos formular una segunda etapa durante el año

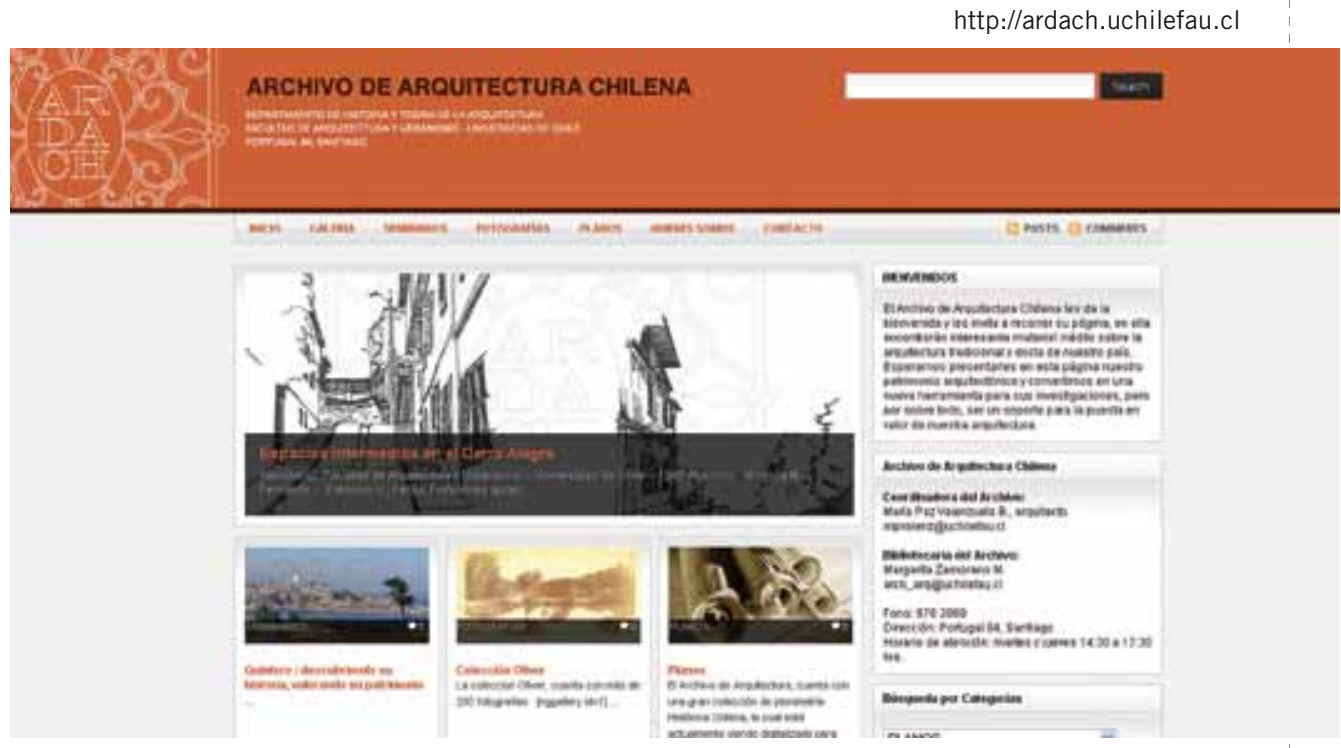

2009, que también fue favorecida con recursos ADAI para el año 2010, ello nos permitirá continuar con la labor de restauración, clasificación y digitalización del material, a la vez de mejorar la página web implementando un formulario de contacto que facilitará la consulta de los usuarios externos.

Con ello esperamos difundir aún más nuestra colección, contribuyendo así al conocimiento y valorización de la arquitectura nacional.

Nuestra colección cuenta con diversos tipos de material documental, entre ellos destacan los Seminarios de Investigación que abordan desde casos monografías de arquitectos hasta el análisis de conjuntos, pasando por los casos particulares de Monumento o edificios patrimoniales. Están catalogados, clasificados e ingresados al Catálogo Bello de nuestra Universidad. Importante es destacar la condición de copia única en muchos de ellos.

Se cuenta además con una colección de fotografías (2.600 aprox.), que corresponden a casos de patrimonio arquitectónico de edificios y viviendas, mayoritariamente en Santiago. Entre ellas se destaca parte de la colección de Oliver (siglo xix) y algunas correspondientes a la década de 1950 en adelante, en blanco y negro. Esta colección se complementa con fotografías en placas de vidrio y diapositivas de importante valor histórico y documental.
Nuestra colección de planos corresponde al complemento gráfico de las investigaciones refrendadas en los Seminarios, muchos de ellos son de gran valor histórico y algunos de carácter original.

Es importante señalar que si bien este proyecto se inició con el aporte ADAl, cuenta también con un importante y sostenido aporte de nuestra Facultad, requisito indispensable para que $\mathrm{AECI}$ siga colaborando con nuestro proyecto.

Por último quisiéramos invitar a los lectores, investigadores y amantes de la arquitectura chilena a visitar nuestra página y contribuir con el Archivo de Arquitectura Chilena a través de donaciones de diverso material documental, el que hoy puede ser conservado adecuadamente y presentado a través de la web. Ello nos permitirá seguir rescatando y poniendo en valor el quehacer arquitectónico nacional, involucrando a las futuras generaciones en su protección y conservación, reconociendo en él la mejor expresión de un desarrollo cultural propio.

Nota: El Archivo funciona físicamente dentro del área correspondiente al Departamento de Historia y Teoría de la Arquitectura y está a cargo de un académico Coordinador, dependiente del Director del Departamento señalado, además cuenta con la colaboración permanente de una bibliotecaria especializada. 